\title{
REFLEXIONES EN TORNO A \\ LA FINALIDAD PEDAGÓGICA \\ DE LA TITULACIÓN
}

Ana María del Pilar Martínez Hernández

\section{RESUMEN}

Se pretende resaltar la finalidad formativa y pedagógica del proceso de titulación, partiendo de que, en la actualidad, este proceso se percibe como un mero trámite académico-administrativo y como un indicador de la eficiencia terminal de las instituciones de educación superior.

Rescatar el sentido pedagógico original que poseían los exámenes en las universidades medievales, podría dar alguna luz sobre la vinculación entre los procesos de formación y la titulación considerada como cierre de un ciclo, así como del peso e importancia que este acto suponía para el sustentante, la institución y la sociedad en su conjunto.

\section{ABSTRACT}

Seeking to highlight the formative and pedagogic goal of the titration process, taking into account the fact that, nowadays, this process is seen merely as an academic-administrative formality, and as an indicator of the terminal efficiency of bigher education institutions. 
To rescue the original pedagogic sense of the examinations in medieval universities could shed some light on the connections between the formative processes and entitlement seen as the closure of a cycle, and the importance this act had upon the scholar, the institution and society as a whole.

Palabras clave: Titulación; obra maestra; exámenes y licencias en la universidad medieval; procesos de formación.

\section{INTRODUCCIÓN}

En la actualidad, la principal preocupación de las instituciones de educación superior en torno a la titulación, se ha centrado en vislumbrarla como uno de los principales indicadores de la eficiencia terminal de la organización educativa. Así, la titulación se concibe como un proceso de carácter académico-administrativo, que como tal puede ser resuelto a través de la reformulación de los reglamentos respectivos y de la apertura de opciones para la obtención del título, de manera que se facilite el trámite y se eleve la cifra de titulados.

Por ejemplo, recientemente, el Consejo Universitario de la Universidad Nacional Autónoma de México ${ }^{1}$-la cual suele ser un modelo a seguir por muchas otras instituciones de educación superior del país, y aun de América Latina-, aprobó las siguientes modalidades de titulación para el nivel de licenciatura: 1) tesis y examen profesional; 2) actividad de investigación; 3) seminario de tesis o tesina; 4) examen general de conocimientos; 5) totalidad de créditos y alto nivel académico; 6) acción de apoyo a la docencia; 7) trabajo profesional; 8)

En sesión del 5 de julio de este año. Véase, Gaceta UNAM., No. 3., 734., 8 de julio de 2004 . 
créditos en posgrado; 9) profundización de conocimientos; y 10) servicio social. Como puede verse, la UNAM parece estar considerando una amplia gama de opciones para incrementar la titulación, muchas de las cuales han sido probadas, y en algunos casos descartadas, por otras instituciones educativas de nivel superior (mexicanas y del extranjero), que las han empleado buscando ampliar sus estadísticas al respecto.

Sin embargo, aunque la experimentación de alternativas a la tesis tradicional y a su defensa ante un jurado, y de mecanismos administrativos tendientes a incentivar la titulación es importante, nos parece que el problema no se ha analizado a fondo en facetas que son de mayor relevancia para entender y resolver el fenómeno del bajo índice de titulados registrado en las universidades.

Desde nuestra perspectiva, la comprensión del problema de la titulación debe situarse en dos dimensiones básicas: la pedagógica (ligada al nivel institucional) y la formativa (ubicada en el nivel individual). Me abocaré a explicar cada una.

La dimensión pedagógica de la titulación se relaciona con lo institucional en dos sentidos: uno externo y otro interno. El primero de ellos, parte de que la concepción egreso-titulación está condicionada por la relación que la institución educativa establece con el contexto social en sentido amplio; es decir, en esta dimensión ubicamos a la titulación como uno de los factores vinculados con las expectativas sociales en torno a la Universidad; la interpretación que ésta hace de las carreras profesionales necesarias o aceptadas socialmente; los perfiles de egreso específicos que cada institución diseña para las carreras que imparte, los cuales "traducen" lo que la institución 
educativa considera de utilidad para atender los requerimientos y necesidades sociales; así como la consideración de las determinantes normativas derivadas del ejercicio de las distintas profesiones ${ }^{2}$.

El segundo aspecto se relaciona con la reglamentación interna de la propia Universidad, respecto a los criterios y mecanismos institucionales para examinar al pasante, los relacionados con la expedición de títulos, así como con el establecimiento de las metas que en materia de egreso-titulación espera alcanzar la Universidad.

Con referencia a esta relación Universidad-contexto, nos permitimos señalar lo que ha ocurrido entre las universidades públicas mexicanas y el Estado, en materia financiera, durante las últimas décadas en que los índices de titulación se han convertido en un criterio decisivo para la asignación de presupuestos, considerando este indicador clave para medir la eficiencia terminal del sistema. Esta situación -nos parecieraes una de las causales que ha pervertido la concepción académica de la titulación y ha propiciado que el interés de la institución se centre en mejorar sus índices de egreso-titulación, a fin de obtener mayores apoyos presupuestales. Sin embargo, la baja titulación es un fenómeno generalizado que afecta a todo tipo de universidades -sean éstas públicas o privadas-, con fuertes repercusiones en términos del rezago en el egreso y de la incidencia de éste en la imagen y el prestigio institucionales. 
Ahora bien, de la relación contexto-institución se desprende la concepción pedagógica a la que queremos referirnos, ya que de aquélla se derivan una serie de aspectos tales como: la planeación institucional; la investigación educativa sobre el análisis de las necesidades sociales y los mercados de trabajo profesionales; el seguimiento de egresados. Y, por ende, el diseño curricular en todas sus dimensiones: la definición de las metas de formación a alcanzar; la concepción disciplinaria y del proceso enseñanza-aprendizaje de la Universidad; los saberes y quehaceres profesionales a enseñar; las actitudes y valores a desarrollar; la estructura, secuencia y articulación de los contenidos a aprender; las modalidades didácticas seleccionadas para las distintas actividades de enseñanza-aprendizaje; la relación docente-discente; los auxiliares didácticos a emplear; las actividades intra clase y extra clase; los criterios y mecanismos de evaluación; los ciclos de retroalimentación de los procesos, y, relacionado con ello, el sentido asignado a la titulación y la inclusión —o exclusión- de ésta dentro de los procesos curriculares de formación del futuro profesionista.

A esta concepción pedagógica general se engarza la dimensión individual a la que aludíamos antes, la cual integra las expectativas particulares y subjetivas de todos y cada uno de los distintos sujetos universitarios. Interesa ahora apuntar y resaltar las características que han asumido las relaciones humanas en la Universidad moderna ${ }^{3}$, las cuales se han vuelto

$\mathrm{Al}$ respecto, C. Bonvecchio señala que la Universidad es el lugar institucional de reproducción de la cultura hegemónica, que con el paso del tiempo se ha visto reducida a: "... "fábricas" de estudiantes, de graduados, de administradores o, según el caso, de desocupados, las universidades desarrollan una acción que frecuentemente se reduce a la "asistencia social" de masas". Cfr. BONVECCHIO, C. (comp.)., El mito de la universidad., p.18. 
cada vez más lejanas e impersonales. La "masificación" de la educación superior; el énfasis en la creación y logro de sistemas más eficientes en lo referente a la planeación, administración y evaluación institucionales; la ausencia de vida colegiada; y el predominio -en la mayoría de las universidades- de la docencia a tiempo parcial, entre otros factores, han modificado la calidad y posibilidad de interacción entre los diferentes actores universitarios: autoridades, personal académico, personal administrativo y estudiantado. Ello -que es propio de las organizaciones modernas, altamente burocratizadas, en el sentido estudiado por Weber ${ }^{4}$ - ha propiciado que la situación del alumnado en las universidades sea, en muchos sentidos, de aislamiento e incluso de indefensión.

Paradójicamente, la didáctica universitaria y el uso de tecnologías en apoyo a la docencia han permitido que el maestro -independientemente de su profesionalización, su adscripción, o la de la institución a una teoría psicológica del aprendizaje- sea cada vez más eficiente y centre su quehacer en, valga la redundancia, su propio hacer, enfocándose en el logro de las metas del programa de su curso, en beneficio -es cierto- del aprendizaje del alumno, pero descuidando la faceta humana y subjetiva de éste, y, en ocasiones, careciendo de una visión más amplia y comprensiva del papel que su materia, asignatura o módulo juega en el proceso de formación integral del estudiante, al centrar su actuación en los objetivos

Max Weber describe con el concepto de burocracia una "organización racional" que maximiza la eficiencia en la administración y cuyo tipo ideal reúne las siguientes características: la especialización de tareas; una jerarquía de la autoridad; un sistema de reglas; impersonalidad; el empleo basado en las calificaciones técnicas; la eficiencia. Véase, Salaman, G. y K. Thompson., Control e ideología en las organizaciones., pp.15-36. 
cognitivos y, en el mejor de los casos, en las actitudes más evidentes que se están desarrollando entre sus estudiantes.

¿Piensa el docente en la titulación durante su enseñanza? ¿Estimula aquellas habilidades requeridas para que el futuro sustentante a obtener un título tenga éxito en este proceso? ¿Coadyuva a que el alumno desmitifique esta ceremonia y se enfoque hacia su consecución? Sinceramente lo dudamos, salvo en el caso de maestros que tengan a su cargo seminarios curriculares dedicados a la titulación. Así, cada uno de los docentes vemos las asignaturas que impartimos como reductos sin líneas de conducción entre unas y otras, lo cual dificulta al estudiante establecer las ligas, transferencias y estructuración cognitiva de los campos que estudia. ¿La titulación? Queda fuera del panorama por su distancia y porque pareciera un problema que deberán atender otros; es decir: ha quedado segmentada de los procesos de formación.

Por su parte, los estudiantes de nivel superior suelen llegar a la Universidad con una serie de preconcepciones con respecto a sí mismos y a lo que la institución les ofrecerá a lo largo de su carrera. Así, llevan a "buen término" su formación profesional, la cual se verá influenciada por una serie de factores institucionales un tanto azarosos (la situación que vive la Universidad, el cambio de un plan de estudios, la incorporación de nuevos maestros, etcétera), así como por condiciones determinantes, que juegan un papel de mayor o menor relevancia en dicha formación. Algunas de estas condicionantes y la fuerza que puedan asumir en el alumno dependen de la historia personal y de la situación vivencial en que éste se encuentre, así como con el proceso individual de desarrollo y madurez por el que atraviese. 
Adquieren aquí un papel fundamental las condicionantes familiares y socioeconómicas en las que se halla inserto el estudiante. Entre éstas pueden mencionarse la posición y el papel que desempeña el sujeto en la familia: ser hombre o mujer, hija o hijo único, primogénito, intermedio o «benjamín"; ser el favorito del padre o la madre; mantener una relación de apoyo o de rivalidad con los hermanos; jugar el rol de madre o padre sustituto, entre otras muchas. O bien, si desarrolla una actividad remunerada mientras realiza sus estudios; el número de horas que dedica a éstos (las cuales incluyen la posibilidad de asistir y permanecer en bibliotecas); si cuenta con un espacio adecuado para estudiar; el tiempo que ocupa en el transporte escuela-casa/casa-escuela; si posee los medios económicos para allegarse instrumentos de apoyo al proceso de aprendizaje (adquisición de libros y materiales necesarios para su formación: equipo de cómputo...), entre otros factores.

Asimismo, entre estas determinantes se encuentran los antecedentes escolares del estudiante: su trayectoria académica previa y los aspectos formativos recibidos durante ésta (instrucción versus formación; desarrollo y adquisición de habilidades cognitivas, motrices, actitudinales y valorativas; fracaso, mediocridad o éxito escolar alcanzado; capacidad para establecer relaciones interpersonales con sus compañeros y maestros); el tener confianza en la escuela como una institución segura, justa y equitativa; el percibirla como un espacio de desarrollo personal o de represión; como un lugar en donde se posibilita la expresión de su creatividad personal; en donde se le respeta como ser humano individual... Aspectos todos ellos que pueden determinar, en gran medida, el deseo de logro, el autoconcepto y la autoestima. 
Todos estos factores nos deben llevar a entender al alumno universitario como un sujeto en proceso de desarrollo, en una edad crítica en la que se espera de él, ya no la crisis de la adolescencia, sino la seriedad y la madurez de un adulto joven seguro de sus decisiones, las que se supone han sido conscientemente asumidas; poseedor de una clara imagen del futuro personal y profesional que le espera, que ha definido las metas y las estrategias para alcanzarlas. ¿Es esto así? ¿Se nos ha ocurrido preguntarles a nuestros alumnos universitarios cómo se ven a sí mismos en cinco, en diez o quince años? ¿Qué harán en lo personal y lo profesional? Realizar este ejercicio -lo aseguramos, ya que lo hemos hecho en repetidas ocasiones con los alumnos-, puede resultar impactante tanto para el docente como para el alumno.

En este discurrir, ¿cómo entienden los alumnos a la titulación? ¿Qué papel juega a lo largo de su trayectoria universitaria? ¿Qué importancia y qué valor tiene para ellos? Si les cuestionamos sobre el lugar que el examen profesional ocupa en sus prioridades personales y profesionales nos encontraremos con un número reducido de alumnos que han integrado este proceso como parte de sus metas y como el fin natural del ciclo de sus estudios superiores. Siempre resulta sorprendente observar el esfuerzo e interés con que los estudiantes de una generación planean su fiesta de "graduación": la importancia que le otorgan a la elección de anillos, diplomas e invitaciones para amigos y familiares, así como el cuidado puesto y la inversión económica en el vestuario para este festejo, considerado $E L$ acto de cierre de sus estudios en la Universidad y no un hecho social simbólico. En ese momento, la elaboración del trabajo de titulación y el examen profesional están en el olvido -intencional o inconscientemente-, 
cubiertos por el velo del espíritu de celebración, el cual eclipsa el reto y la inseguridad que aquel "asunto innombrable" les genera. No olvidemos lo selectiva que puede ser nuestra mente.

¿Por qué es esto así? Para contestar esta pregunta haremos referencia a algunos antecedentes históricos de la Universidad que pueden proporcionarnos una idea de cómo hemos olvidado la dimensión pedagógica de la titulación y con los cuales pretendemos cerrar este escrito.

Como bien sabemos, la Universidad medieval fue un fenómeno educativo sin precedentes por la manera en que surgió, así como por las características y atribuciones de la sociedad donde fue gestada: la Universidad fue un producto de las circunstancias de su época, dada la necesidad de un tipo de instrucción más profana y amplia que demandaba un grupo social específico ante las limitaciones de la oferta educativa brindada por la educación caballeresca, la gremial y la ofrecida por las escuelas monásticas y catedralicias prevalecientes en esa época. Esta "universitas de estudios", tuvo como modelo de organización a la agrupación formada por "la totalidad de personas que se dedicaban a un determinado oficio" ${ }^{5}$, me refiero a los gremios. De éstos, la Universidad no sólo tomó su idea fundamental de agrupación con miras a alcanzar un fin determinado, sino que logró un paralelismo acentuado con éstos, en cuanto a la concesión de privilegios otorgados por el poder real y el pontificio. 
Igualmente, la Universidad asumió del gremio artesanal, la forma de organización fundamentada en la especialización y el desarrollo de habilidades y capacidades, ya que el gremio tenía:

"[...] como fin esencial, junto con el ejercicio de su arte y la protección de sus asociados, la exigencia de ir formando a sus propios cuadros para mantener la continuidad, de este modo elaboraron un esquema de instrucción técnico-profesional enfocado a desarrollar las habilidades necesarias para la industria y el comercio. Es así como el taller o pequeña fábrica se convirtió en escuela de oficios en la que se daba una educación formativa en la que cada arte o ministerium implica en sí una escuela y se identifica con ella" ${ }^{6}$.

Los miembros de un gremio artesanal eran: el "maestro", quien dominaba el oficio y por ello había alcanzado la maestría; asimismo, dado su estado podía formar, promover y facultar a nuevos maestros; el "aprendiz" que era quien aprendía el oficio de un maestro autorizado o licenciado para enseñarlo y ejecutarlo; y el "jornalero" u "oficial", persona que poseía un alto conocimiento del arte y trabajaba bajo las órdenes de un maestro.

El aprendiz generalmente vivía en la casa del maestro, dueño del taller, con quien los padres habían celebrado un convenio para que se le enseñara el oficio. Así, iba adquiriendo paulatina y gradualmente el conocimiento, habilidades y actitudes asociadas con la profesión, a través de la práctica de tareas que iban de lo simple a lo complejo. Debían transcurrir varios años de aprendizaje, antes que el joven fuese 
examinado por el gremio y, de ser aprobado, se le extendía el título de "oficial"; entonces participaba como un igual en la producción a cambio de un modesto salario. Quien optaba por obtener el más alto grado de reconocimiento gremial a su desempeño, podía someterse a un nuevo examen que le permitía adquirir el grado de "maestro". Este examen consistía en la elaboración de una "obra maestra" en la que quedara demostrada la posesión de la maestría en el oficio ${ }^{7}$. La "maestría", certificada por el gremio, implicaba la libertad para instalar un taller propio, el contar con voz y voto en las asambleas del gremio y el reconocimiento de índole socioeconómica, respaldado por la fuerza que le otorgaba la corporación.

Cabe señalar que el proceso de formación seguido en este modelo de educación artesanal para conseguir la maestría, posee características pedagógicas singulares ${ }^{8}$, algunas de las cuales interesa subrayar: es personalizado, por tanto, respeta el ritmo de aprendizaje del alumno; asimismo, al tiempo que se adquiere este aprendizaje, se produce el objeto mismo sobre el que se está adquiriendo el arte de su ejecución; es continuo y gradual, regulado por las necesidades del estudiante .

Sobre este aspecto véanse, entre otras, las obras de L. Huberman y J. Jacques incluidas en el apartado de referencias bibliográficas.

8 Para una caracterización amplia de este modelo de educación, comparado con el modelo escolar, véase Moreno E. y De los Arcos, E., Hacia una teoría pedagógica., México, Colegio de Pedagogos de México/UNAM., Seminario de Pedagogía Universitaria., 1999., p.133.

9 Dado que este proceso se desarrollaba dentro del taller artesanal, podemos entender la derivación lingüística que se otorga a la modalidad didáctica actual denominada taller, la cual como actividad de enseñanza-aprendizaje debe obtener como resultado un "producto", en el cual se demuestre fehacientemente la apropiación del aprendizaje por parte del estudiante. 
Como señalamos, las universidades surgieron como asociaciones de alumnos y maestros, al estilo de los gremios, para el estudio de un determinado campo del saber entre los siglos XII y XIII de nuestra era. Los estudiantes con capacidad económica, empezaron a constituir grupos que contrataban a ciertos docentes de fama reconocida, con la finalidad de que éstos les impartiesen los conocimientos por ellos requeridos. Los maestros, casi todos ellos provenientes de las escuelas catedralicias, de claro enfoque escolástico, formaron a su vez corporaciones que ofrecían sus servicios académicos. De esta manera, al ser resultado de procesos de organización de la sociedad civil, las universidades pudieron manejarse, inicialmente, con relativa independencia de la autoridad religiosa y política de su tiempo. Sólo posteriormente, por las ventajas que significaba para ellas, se acogieron a la protección de los monarcas y el papado ${ }^{10}$. Entre los privilegios con que contaban se encontraba la exención del pago de impuestos y la realización del servicio militar, así como la inmunidad de arresto por parte de las autoridades civiles; además, tenían autonomía para gobernarse y administrar sus bienes.

Las universidades también copiaron a los gremios la estructura de aprendizaje graduada en niveles y la certificación que se otorgaba en cada uno de éstos. Estaban organizadas académicamente en "facultades", las cuales, además de designar la rama de estudio especializada que en ella se estudiaba, se referían al derecho de la institución a expedir "grados". El primer nivel era preparatorio, no profesional, y se

${ }^{10}$ Hubo universidades a las que no les interesó contar con una carta de fundación; otras que contaron con carta de fundación papal o real, o con ambas. 
impartía en la Facultad de Artes, la cual otorgaba el título de "bachiller", requisito para ser admitido en las otras facultades. Éstas, de nivel superior, enseñaban Derecho, Medicina y Teología, y extendían los grados académicos de "maestría" y "doctorado". De acuerdo con Atkinson y Maleska:

"El estudiante solía ingresar en la universidad a los catorce años. Una vez admitido, elegía a un maestro con el cual estudiaba hasta que podía "definir" y "determinar", esto es, hasta que era capaz de leer, escribir y hablar latín. Si pasaba el examen que se le hacía sobre estas materias, recibía el título de "bachiller". Luego, durante un período de cuatro a siete años, proseguía sus estudios bajo la tutela de varios maestros hasta que podía "discutir", esto es defender su tesis u "obra maestra". Si tenía éxito en su defensa, [...] era admitido como maestro" ${ }^{11}$.

Además de los grados de maestro y doctor, las facultades expedían la licentiae docendi que brindaba a quien la poseyera, la posibilidad de enseñar dentro de la misma institución. Si la universidad que expedía esta licencia contaba con carta de autorización real o pontificia (o ambas), otorgaba a sus egresados la licentiae docendi ubique, es decir, la licencia para enseñar en cualquier otra Universidad que contara con reconocimiento del Papa o del monarca.

Como puede inferirse, las universidades fueron desarrollando una rigurosa sistematización tanto de la enseñanza como de sus procesos de evaluación y expedición de grados. 
Existía un esquema preciso de programación de los distintos cursos, se leía a los mismos autores y textos, se seguía una metodología didáctica específica y se contaba con un rígido conjunto de indicadores que guiaba el sistema de exámenes, todo lo cual facilitaba el reconocimiento inter-institucional y la movilidad estudiantil y de docentes, que en la actualidad estamos lejos de resolver.

Nos interesa remarcar que el método didáctico empleado comúnmente -herencia de la escolástica-, comprendía tres etapas: lección, repetición y disputas.

"La lección o lectio consistía en la exposición, normalmente por parte del maestro, de ciertos libros y autores], como base de la enseñanza (libros canónicos). Después tenían efecto las repeticiones [repetitio], que eran las explicaciones y comentarios de las partes difíciles de la lección, en forma de diálogo entre maestros y alumnos [...] Como medio para estimar el aprovechamiento, así como recurso instructivo, existía la disputatio [o disputa]. Se verificaba semanariamente; concurrían a ella los profesores y alumnos de la facultad. Un magister pronunciaba una conferencia. Los demás profesores apoyaban u objetaban los puntos de la ponencia (tesis). La disputatio era a modo de una parada, en que la facultad exhibía su arte y su clientela, [...] era un expediente magnífico para desarrollar la destreza dialéctica" ${ }^{12}$.

Como puede desprenderse de la cita anterior, el estudiante se formaba observando el proceso de construcción lógica y de defensa pública de una tesis e iba, paulatinamente, participando en dicho proceso, de acuerdo con las habilidades

12 Larroyo, F., Historia general de la Pedagogía., pp.288-289 (el subrayado es mío). 
lógicas de construcción y defensa de argumentos, así como de escritura y de oratoria, adquiridas a lo largo de su estancia en las aulas universitarias. Esta metodología, aunada a la realización de trabajos de investigación, escritos y prácticos, así como a la asistencia cotidiana y uso consistente de la biblioteca, configuraban el estilo y la forma de vida en la Universidad. El escolar sabía con toda claridad qué se le pediría realizar al término de sus estudios para poder aspirar a los grados y licencias referidos: debía elaborar una tesis escrita siguiendo los cánones estipulados y defenderla públicamente ante un jurado compuesto por maestros y doctores, quienes de aprobarlo se convertirían en sus pares. El acto mismo era de enorme relevancia no sólo para el sustentante sino para la institución que se preciaba de graduar a un nuevo maestro o doctor y lo hacía públicamente, ante la sociedad, con grandes y pomposos festejos.

Lejos estamos el día de hoy de entender este proceso como lo hacía la Universidad primigenia. Nos interesa enfatizar cómo la Universidad moderna ha tendido a juzgar la titulación como un mero trámite, y ha perdido la oportunidad de considerarla como un proceso formativo para el estudiante, que puede permitirle la consolidación de los conocimientos y habilidades adquiridas a lo largo de su carrera, en un ejercicio de integración de saberes y quehaceres, actitudes de crítica y autocrítica, sin menoscabo de su autoestima. Asimismo, minimiza la posibilidad de ver en este proceso un reflejo claro que le permita evaluar su quehacer institucional, valorando la atingencia de su tarea primordial: la formación profesional recibida por sus estudiantes. 
Para concluir, enfatizamos que nos preocupa observar como día a día las instituciones de educación superior en México, buscan elevar sus índices de eficiencia terminal «facilitando" al egresado la titulación, a través de criterios y mecanismos de carácter administrativo, perdiendo la perspectiva académica y la oportunidad de llevar a cabo este ejercicio pedagógico último (al menos simbólicamente para la institución y el egresado), que debería conducir: al sustentante, a un aprendizaje más que le confiriera un sentimiento de logro personal y profesional; a los docentes, a la constatación del valor de su tarea y sus enseñanzas; y a la institución, a la confirmación de haber cumplido con los fines que la sociedad le ha encomendado. 


\section{REFERENCIAS BIBLIOGRÁFICAS}

ATKINSON, C. y E. T. MALESKA., Historia de la educación., Barcelona., Martínez Roca., 1966., 499 págs.

BONVECCHIO, C. (comp.)., El mito de la universidad., México., UNAM/Siglo XXI., 2002., 285 págs.

GARCÍA ROBLES, A., La Sorbona ayer y hoy. Sinopsis histórica de la Universidad de París desde sus orígenes hasta nuestros días., México., UNAM., 1943., 162 págs.

HUBERMAN, L., Los bienes terrenales del hombre. Historia de la riqueza de las naciones., México., Nuestro Tiempo., 1978., 378 págs.

JACQUES, J., Las luchas sociales en los gremios., Madrid., Miguel Castellote Editor., s/a., 164 págs.

MARTÍNEZ HERNÁNDEZ, A. M. del P., "Nombres nuevos para prácticas antiguas", en Paedagogium. Revista mexicana de educación y desarrollo., Año 2., No. 8., pp. 20-22.

MONDOLFO, R., Universidad: pasado y presente., Buenos Aires., Editorial Universitaria de Buenos Aires., 1966., 75 págs. MORENO Y DE LOS ARCOS, E., Hacia una teoría pedagógica., México., Colegio de Pedagogos de México/ UNAM., Seminario de Pedagogía Universitaria., 1999., 133 págs.

SALAMAN, G. y K. THOMPSON., Control e ideología en las organizaciones., México., fce., 1984., 366 págs. 